\title{
Therapeutic potential of oncolytic Newcastle disease virus: a critical review
}

This article was published in the following Dove Press journal:

Oncolytic Virotherapy

27 March 2015

Number of times this article has been viewed

\author{
Shay Tayeb ${ }^{1,2}$ \\ Zichria Zakay-Rones ${ }^{2}$ \\ Amos Panet ${ }^{2}$ \\ 'Department of Biotechnology, \\ Hadassah Academic College, \\ Jerusalem, Israel; ${ }^{2}$ Department of \\ Biochemistry and Molecular Biology, \\ The Chanock Center for Virology, \\ Institute of Medical Research Israel- \\ Canada, The Hebrew University- \\ Hadassah Medical School, Jerusalem, \\ Israel
}

\begin{abstract}
Newcastle disease virus (NDV) features a natural preference for replication in many tumor cells compared with normal cells. The observed antitumor effect of NDV appears to be a result of both selective killing of tumor cells and induction of immune responses. Genetic manipulations to change viral tropism and arming the virus with genes encoding for cytokines improved the oncolytic capacity of NDV. Several intracellular proteins in tumor cells, including antiapoptotic proteins (Livin) and oncogenic proteins (H-Ras), are relevant for the oncolytic activity of NDV. Defects in the interferon system, found in some tumor cells, also contribute to the oncolytic selectivity of NDV. Notwithstanding, NDV displays effective oncolytic activity in many tumor types, despite having intact interferon signaling. Taken together, several cellular systems appear to dictate the selective oncolytic activity of NDV. Some barriers, such as neutralizing antibodies elicited during NDV treatment and the extracellular matrix in tumor tissue appear to interfere with spread of NDV and reduce oncolysis. To further understand the oncolytic activity of NDV, we compared two NDV strains, ie, an attenuated virus (NDV-HUJ) and a pathogenic virus (NDV-MTH-68/H). Significant differences in amino acid sequence were noted in several viral proteins, including the fusion precursor (F0) glycoprotein, an important determinant of replication and pathogenicity. However, no difference in the oncolytic activity of the two strains was noted using human tumor tissues maintained as organ cultures or in mouse tumor models. To optimize virotherapy in clinical trials, we describe here a unique organ culture methodology, using a biopsy taken from a patient's tumor before treatment for ex vivo infection with NDV to determine the oncolytic potential on an individual basis. In conclusion, oncolytic NDV is an excellent candidate for cancer therapy, but more knowledge is needed to ensure success in clinical trials.
\end{abstract}

Keywords: Newcastle disease virus, NDV-HUJ, oncolysis, immunotherapy, models

\section{Introduction}

Our extensive knowledge of the molecular mechanisms underlying the development of cancer has not been translated fully to the development of optimal treatment modalities, and cancer is still the leading cause of death in the developed world. Since oncolytic viruses preferentially infect and kill cancer cells, and consequently stimulate long-term immune responses against tumors, viral oncolysis may well serve as a novel approach for treating cancer in combination with standard therapies or where conventional therapies have failed. ${ }^{1,2}$

\section{Brief history of oncolytic viruses}

The first evidence for virotherapy was reported in 1912 by De Pace, who showed major tumor regression following rabies vaccination in cancer patients. ${ }^{3}$ Initially, oncolytic 
virotherapy was carried out with wild-type viruses grown in cell cultures or fertilized eggs. The second-generation oncolytic viruses were based on genetically modified viruses to enhance the efficacy of treatment. Third-generation oncolytic viruses include "armed viruses" cloned with toxic genes or immune stimulatory genes, such as interleukin-2 and granulocyte macrophage colony-stimulating factor, in order to activate an immune response against cancer cells and increase tumor destruction. ${ }^{2,4}$ Several DNA and RNA viruses, including vaccinia, adenovirus, measles, and Newcastle disease virus (NDV) are currently being used as oncolytic viruses in advanced clinical trials. The genetically modified Adeno-5 (H101) virus was approved for the treatment of cancer in 2005 by the government of the People's Republic of China, and herpes simplex virus type 1 (HSV1; T-Vec, Amgen Inc., Thousand Oaks, CA, USA) was approved by the US Food and Drug Administration in 2013 as an oncolytic virus. ${ }^{5,6}$ Extensive descriptions of the pioneering works in the field of viral oncolysis have been published by Moore, ${ }^{7}$ Kapp, ${ }^{8}$ and Ring. ${ }^{9}$ Csatary in 1971 was the first to report regression of aggressive metastatic colon cancer in a Hungarian farmer following an outbreak of NDV on his farm, suggesting a correlation with NDV infection. ${ }^{10}$

\section{Newcastle disease virus}

NDV is a paramyxovirus of spherical shape, $150 \mathrm{nM}$ in diameter, and with a bilayer lipid envelope. The viral genome is a non-segmented, single-stranded RNA of negative polarity. The viral genome contains six genes: nucleoprotein (NP) phosphoprotein $(\mathrm{P})$, matrix protein $(\mathrm{M})$, fusion protein $(\mathrm{F})$, hemagglutinin-neuraminidase (HN), and large protein (L). The RNA-dependent RNA polymerase complex contains the $\mathrm{L}, \mathrm{P}$, and NP proteins. ${ }^{11}$ Through an overlapping reading frame, the $\mathrm{P}$ gene encodes yet another product, the $\mathrm{V}$ protein, which serves as an interferon (IFN) type 1 antagonist in avian hosts. ${ }^{12,13} \mathrm{~F}$ is translated as a precursor (F0), and only after proteolytic cleavage gives the mature F1 and F2, ie, the virus that can fuse with the cell membrane to become infective. ${ }^{14,15} \mathrm{NDV}$ naturally infects poultry, with different levels of pathogenicity depending on the virulence of the virus. ${ }^{11,16} \mathrm{NDV}$ is usually not pathogenic to humans, although it may cause minor transient symptoms, such as conjunctivitis and flu-like symptoms.

NDV strains are divided into three groups based on their virulence in chickens; however, the different strains are not distinguishable by serology. ${ }^{11,16,17}$ Velogenic strains of NDV are the most virulent, causing severe disease that results in almost $100 \%$ death of infected chickens. ${ }^{18}$ Mesogenic NDV are mid-virulent strains, causing respiratory disease in chicks and young chickens and lowering egg-laying ability. Mortality post infection is about 25\%. Among the mesogenic NDV strains with proven oncolytic activity are MTH-68/H and PV701 strains. ${ }^{19-21}$ Lentogenic, or non-virulent attenuated strains, cause only mild symptoms in the avian respiratory tract without mortality. ${ }^{22}$ At present, it is acceptable to vaccinate poultry only with lentogenic strains (such as NDV Hitchner-B1, Ulster, and LaSota), while the mesogenic strains are considered an agriculture hazard. Therefore, lentogenic NDV strains have been applied extensively as oncolytic viruses.

One of the viral proteins associated with pathogenicity in avian is the F protein. Once the cleavage site in the precursor F0 polyprotein, to give mature $\mathrm{F} 1$ and F2, is sensitive to cellular serine proteases, due to multiple basic amino acid sequences, the virus efficiently infects and spreads in a variety of tissues and is thus pathogenic. ${ }^{11,23,24}$

\section{Oncolytic NDV}

The oncolytic potential of NDV has been demonstrated in cell cultures, in experimental animal models, and in clinical trials, with both pathogenic (MTH-68/H, Ulster, and PV701) and non-pathogenic (Hitchner-B1, LaSota, 73-T, and HUJ) virus strains. ${ }^{10,21,25-31}$ NDV-HUJ (Hebrew University Jerusalem) is an attenuated strain, isolated in our laboratory from the vaccine NDV Hitchner-B1 strain. NDV Hitchner-B1 has been passaged repeatedly in the allantoic cavity of 10-day-old embryonated eggs and cloned by the limited dilution method. The HUJ strain is highly attenuated, as indicated by an Intracerebral Pathogenicity Index (ICPI) of 0.01, obtained after intracranial injection in 1-day-old chicks, compared with the ICPI of 0.39 found with most avian vaccine strains. ${ }^{32}$ Sequence analysis of the NDV-HUJ genome, compared with that of two other attenuated strains, NDV Hitchner-B1 and NDVLaSota, uncovered a unique chimera with genome homology to both NDV Hitchner-B1 and NDV-LaSota strains. Notably, the amino acid sequence at the proteolytic cleavage site in between F1 and F2 is unique to the HUJ strain (Figure 1). ${ }^{33}$ This sequence is a major determinant of NDV pathogenicity and may govern the distinct properties of NDV-HUJ.

\section{Methodologies in oncolytic NDV research}

To explore the oncolytic activity of the different viruses, most studies have used classic cell culture techniques and animal models, mostly mice. Notwithstanding, multiple promising models applied to assess the oncolytic activity of various viruses failed the final judgment of clinical trials, so some 

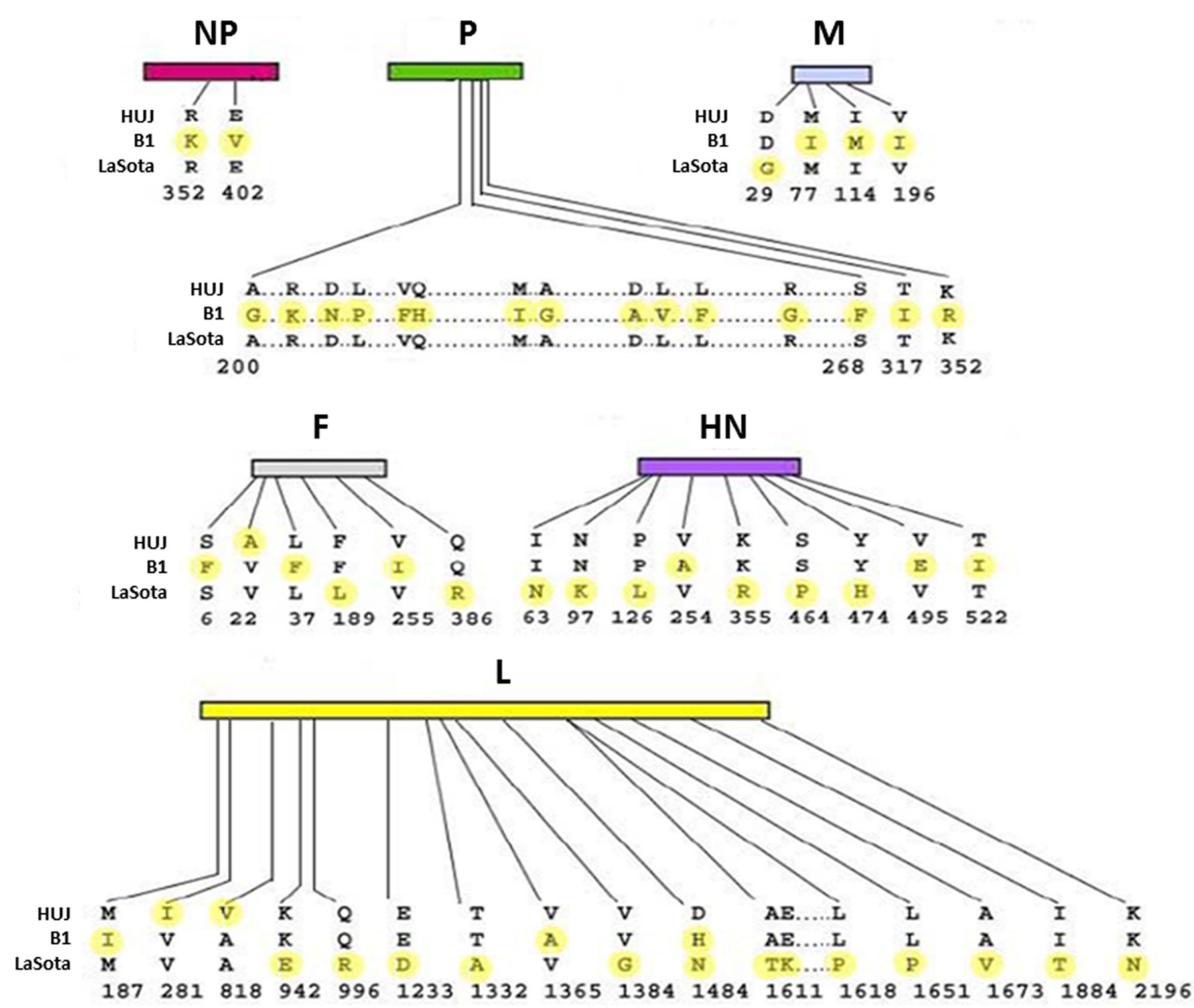

Figure I Protein sequence comparison of three NDV strains. Hitchner-BI, Lasota, and HUJ protein sequences were compared using the Clustalw program. Differences between the protein amino acids of the three strains are marked in yellow.

Abbreviations: NDV, Newcastle disease virus; HUJ, Hebrew University Jerusalem; NP, nucleoprotein; P, phosphoprotein; M, matrix protein; F, fusion protein; HN, hemagglutinin-neuraminidase; L, large protein.

validation of the experimental models is required before entering the clinical phases.

\section{Cell cultures}

Cultures of human tumor cells are routinely used for initial assessment of viruses with potential oncolytic activity and to decipher the mechanism of oncolysis. ${ }^{34-36}$ Among the advantages of the cell culture system are its simplicity and the ability to use tumor cells of human origin. However, tumor cell lines often differ genetically from the primary cells of the original tumor due to extensive mutations in culture, and in many cases the normal cell equivalent of the tumor cell cannot be propagated.

\section{Animal models}

Mouse models have been most commonly used in advanced stages of preclinical analysis of oncolytic viruses. ${ }^{37-41}$ Results from animal models are usually requested by health authorities for authorization to advance from the research phase to the level of clinical trials. However, given that most oncolytic viruses, including Adeno, HSV 1, NDV, and measles are not naturally mouse viruses, their tropism in mice may not reflect the human situation.

\section{Organ culture}

We have used organ culture methodology extensively in our studies of oncolytic viruses. Fresh human cancerous and adjacent normal tissues are obtained from the operating room (after informed consent) and dissected with a microtome to thin slices $0.3-0.5 \mathrm{~mm}$ in width. The tissue slices are kept as an organ culture using specific medium optimized for each type of tissue (Figure 2). ${ }^{30,42}$ Viability of the tissues in culture is routinely tested on a daily basis using the MTT 3-(4,5dimenthylthiazol-2-yl)-2,5-diphenyltetrazolium bromide assay and the glucose consumption test. ${ }^{42,43}$ Histology analysis indicates the original three-dimensional structure of the 


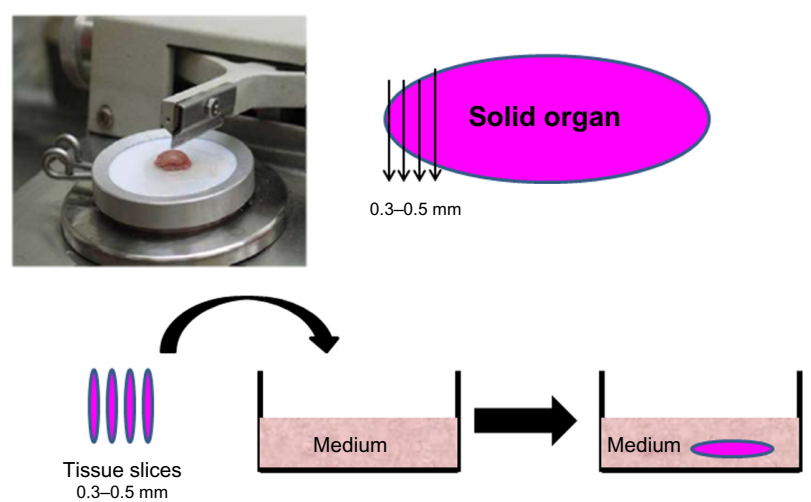

Figure 2 Preparation of organ culture from normal and tumor tissues. Fresh tissues obtained from the surgery room are dissected with a microtome to a width of $0.3-$ $0.5 \mathrm{~mm}$ per slice. Tissue slices are maintained in an optimized medium to preserve viability.

tissue, including the variety of cell and extracellular matrix (ECM) components. ${ }^{30,44}$ Using the organ culture system, we observed that viral tropism is dependent not only on the type of receptor expressed on the cell surface but also on the ECM that is unique to each tissue in the body. As with other models, the organ culture experimental method has its pros and cons in reflecting the human situation. One major advantage for research on oncolytic viruses is that we can simultaneously compare the virus activity in cancerous tissues versus normal tissues in the same patient. Second, comparison of virus oncolytic activity in tumor tissues derived from mice and humans indicates whether the animal model is relevant to the human situation. Validation of the mouse model is especially important when the oncolytic activity of viruses, such as adenovirus, HSV1, and NDV, which are not of mouse origin, is evaluated. However, it should be noted that while the organ culture system is closer to the human situation in the evaluation of oncolytic viruses, it lacks a blood circulation, systemic immunity, or organ boundaries, all of which might influence the clinical efficacy of the virus in the patient and are not reflected in the ex vivo model. ${ }^{30,42,44,45}$ Organ culture technology can also be used to assess the optimal treatment for an individual patient. A biopsy of cancerous tissue is taken from the patient, applied as an organ culture, and infected ex vivo with the oncolytic virus. The effect on the individual tumor tissue is subsequently analyzed by biochemical techniques. This way we may be able to fill the missing links between the research stage and clinical application..$^{30,44}$

\section{Mechanisms of NDV-induced oncolysis}

Several mechanisms for the oncolytic activity of NDV have been described: first, a direct cytopathic effect following selective infection and spread of the virus in tumor cells, ${ }^{15,34,46}$ and second, an indirect effect through recruitment of the innate and adaptive arms of the host immune system. Both natural killer cells and cytotoxic $\mathrm{T}$ lymphocytes directed against viral antigens in infected tumor cells participate in the oncolytic activity. ${ }^{39,47-49}$ Oncolysis through a combination of both direct viral infection and immune mechanisms has also been demonstrated. ${ }^{39}$

The molecular mechanisms via which NDV selectively kills tumor cells have been studied by several investigators. ${ }^{34,50,51}$ Krishnamurthy et al showed that NDV replicates to higher titers in human cancer cells than in normal cells. ${ }^{50}$ Yaacov et al reported that the A549 human non-small lung carcinoma cancer cell line is very sensitive to NDV-HUJ infection, while non-tumorigenic human lung (MRC5) cells are resistant to viral infection. ${ }^{15}$ Moreover, a recent study in our laboratory using organ culture of tissues from patients with colorectal carcinoma indicated selective infection and higher replication of NDV-HUJ in carcinoma tissue than in adjacent normal tissue (Figure 3). Selective NDV infection in tumor tissue ex vivo points to a unique tumor environment facilitating oncolysis in the absence of an immune response.

\section{Intracellular factors affecting the oncolytic activity of NDV}

In contrast with some other oncolytic viruses, the selective antitumor activity of NDV is not dependent on its ubiquitous sialic acid receptor but rather on intracellular factors.

\section{The interferon (IFN) system}

Viruses have evolved sophisticated genetic systems designed to overcome the antiviral activity induced by IFN upon infection of the cell. ${ }^{52-54}$ The interplay between the cellular antiviral systems and the viral antagonistic gene products ("the arm race") determines the extent of viral replication and spread. The IFN system has been studied in some detail with respect to NDV-induced oncolysis. Lorence et al suggested that cancer cells in general are defective in IFN responses and are therefore more sensitive to NDV infection than their equivalent normal cells. ${ }^{55}$ Indeed, defective IFN systems, owing to either lack of induction of IFN or a deficiency of an IFN-stimulating gene response following viral infection, were reported in some cancer cell lines in culture.$^{50}$ In agreement, our studies in fresh tissues taken from twelve colon carcinoma patients indicate that infection with NDV-HUJ induced the IFN system in normal tissues but not in tumor tissues kept as organ cultures. Moreover, we demonstrated induction of the 


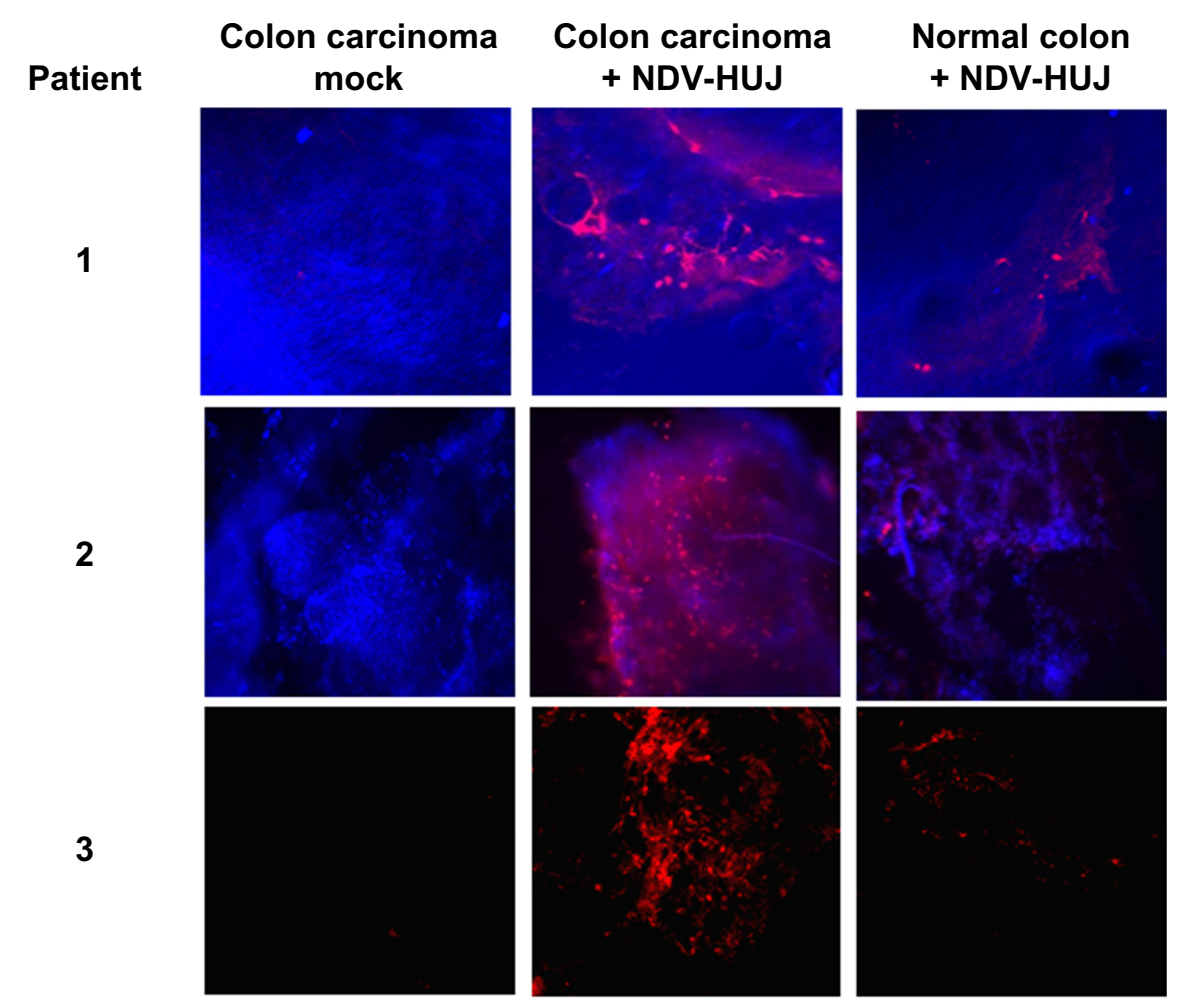

Figure 3 NDV selectively infects human colorectal cancer tissues.

Notes: Slices of normal and cancerous human colon tissues were maintained in organ culture ${ }^{42}$ and the tissues were infected with NDV-HUJ (I $0^{7}$ IU). Forty-eight hours post infection, NDV proteins in the tissue were detected in situ using the polyclonal antibody against NDV. The results shown are three representative tissues from I8 patients. In 17 of 18 cancerous tissue samples, NDV protein expression was significantly higher compared to the infected normal tissue of the same patient. Viral infection is indicated by red color (Cy5 dye), while blue color indicates cell staining (DAPI).

Abbreviations: NDV, Newcastle disease virus; HUJ, Hebrew University Jerusalem.

mRNA for the IFN-stimulating gene, $M X 1$, in normal tissue but not in tumor tissue post NDV-HUJ infection (Figure 4). These observations appear to provide an explanation for the selective oncolytic activity of NDV, at least in some tumors. Nevertheless, many tumors, including melanoma, have a functional IFN system identical to that of normal cells, and yet NDV demonstrated selective replication and oncolytic activity in those tumor cells. ${ }^{15,34}$ Thus, other mechanisms, independent of the IFN system, must facilitate the specificity of NDV for those tumors.

As noted, the NDV genome encodes for the nonstructural $\mathrm{V}$ protein, which in avian cells, though not in mammalian cells, acts as an IFN antagonist. ${ }^{13}$ Therefore, replication of NDV in mammalian cells, whether cancerous or normal, with a competent IFN system is expected to be suppressed. Indeed, when the influenza NS1 gene, which is known to antagonize the IFN system in mammalian cells, ${ }^{52,54}$ was inserted into NDV Hitchner-B1 genome, the resulting NDV chimera replicated to higher titers and exhibited an enhanced oncolytic effect in a variety of human tumor cell lines and in a mouse model of B16 melanoma. ${ }^{40}$

\section{Involvement of antiapoptotic proteins in selective oncolytic activity of NDV}

Several studies have indicated that the oncolytic activity of NDV is associated with the apoptosis cascade, via either the intrinsic or extrinsic apoptotic pathways. ${ }^{56}$ We previously reported that NDV-HUJ efficiently induces the intrinsic apoptotic pathway upon infection of lung cancer cells and of chemoresistant primary melanoma cells. ${ }^{15,34}$ Surprisingly, primary melanoma cell cultures from tissues of patients with advanced melanoma (stage IV) were much more susceptible to the virus than cells taken from early melanomas (stage I and II). ${ }^{34}$ Since both early and advanced melanoma cells have a fully functional IFN system, we investigated other cellular pathways that may differ between the cells to explain the selectivity of NDV-induced oncolysis. A main difference found between the advanced and early stage melanoma cells is overexpression of the Livin protein, which belongs to the family of inhibitors of apoptosis proteins. ${ }^{57}$ The Livin protein is unique among the group of inhibitors of apoptosis proteins as cleavage at position 52 from its amino terminus end by caspase 3 protease turns the protein activity from 


\section{MX1 mRNA levels}

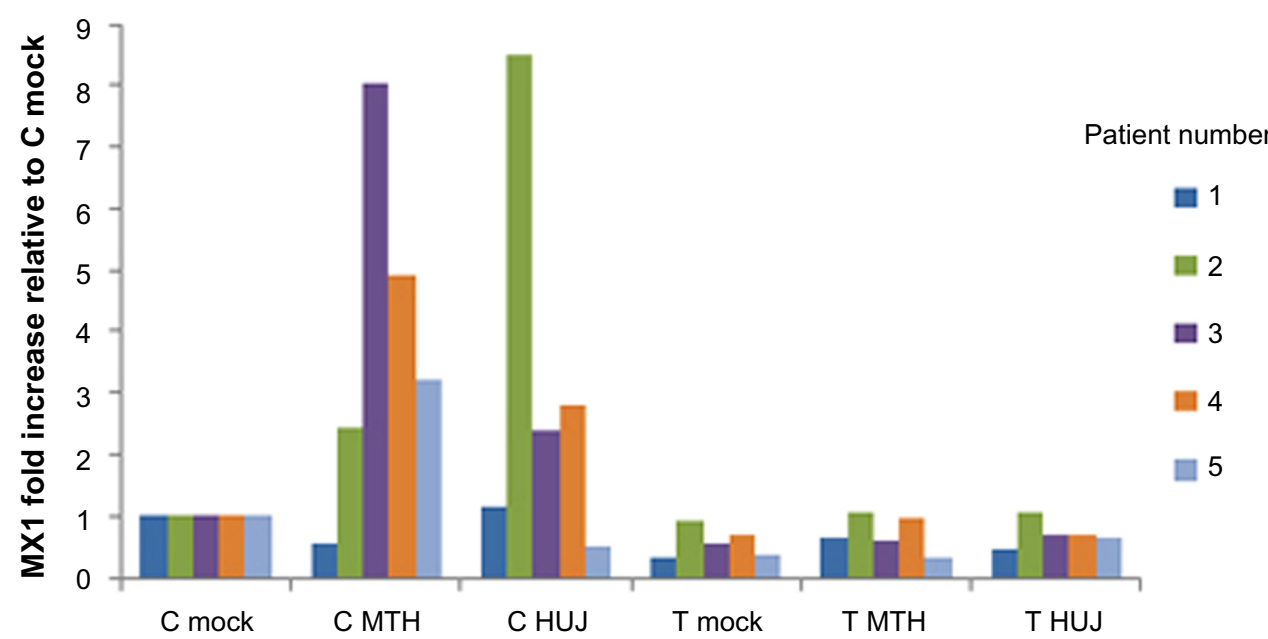

Figure $4 \mathrm{MXI}$ mRNA expression following NDV-HUJ and NDV-MTH-68/H infection in normal and cancerous colon tissues.

Notes: Human normal (C) and cancerous (T) colon tissues in organ culture were infected with NDV-HUJ ( $\left.10^{7} I U\right)$. The interferon stimulating gene $M X I$ mRNA was quantified using quantitative polymerase chain reaction. Following viral infection there is a clear upregulation of MXI mRNA in the normal tissue but not in the cancerous tissue. Each color bar refers to a patient. MXI mRNA expression level is normalized to the expression of the house keeping gene glyceraldehyde-3-phosphate dehydrogenase mRNA.

Abbreviations: NDV, Newcastle disease virus; HUJ, Hebrew University Jerusalem.

antiapoptotic to proapoptotic. ${ }^{57-59}$ Unexpectedly, we found that infection of advanced melanoma cells with NDV-HUJ mediated the cleavage of Livin and thus stimulated the caspase cascade into efficient apoptosis (Figure 5). ${ }^{34}$ It is not yet clear whether any of the NDV gene products are directly involved in the proteolysis of Livin into a proapoptotic protein, or perhaps the effect of infection is indirect through activation of caspase 3 . In yet another study, overexpression of the antiapoptotic BCL-xL protein, which is associated with tumor resistance to cytotoxic drugs, was related to a higher replication capacity of attenuated NDV (LaSota) and consequently to apoptosis in an A549 human lung cancer cell line. ${ }^{35}$ Further, in NDV-infected colon carcinoma cells, the viral matrix protein $\mathrm{M}$ activates the proapoptotic Bax protein (a member of the Bcl-2 protein family) to induce oncolysis in tumor cell lines. ${ }^{60}$ Another oncogenic route involved with

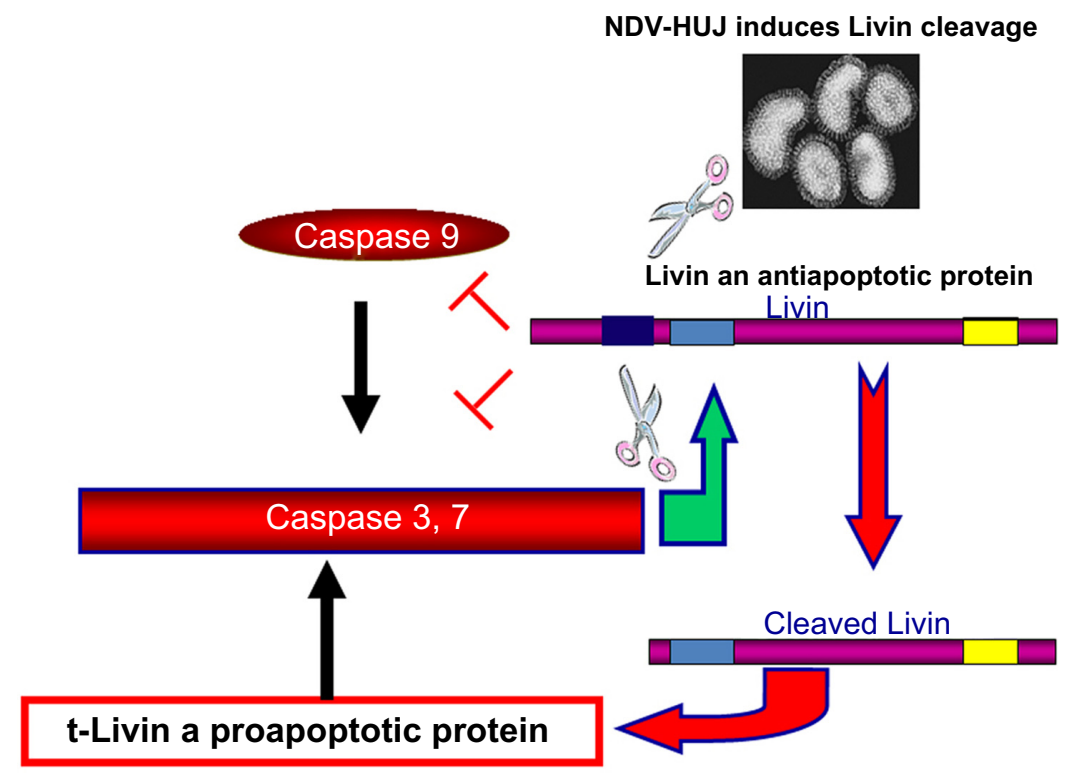

Figure 5 Oncolytic activity of NDV-HUJ in melanoma is Livin-dependent.

Notes: Advanced (stage IV) human melanoma cells overexpress the IAP Livin protein. Once Livin is cleaved, its activity reverts from antiapoptotic into proapoptotic. NDV-HUJ was found to facilitate the cleavage of Livin in advance melanoma cells. ${ }^{34}$

Abbreviations: NDV, Newcastle disease virus; HUJ, Hebrew University Jerusalem. 
cell permissiveness to NDV infection relates to the H-Ras and the GTPase Rac1 gene products. ${ }^{61}$ It has been shown that while the HaCat epidermal cell line is not sensitive to NDV, transformation of the cell by H-Ras resulted in permissiveness to the virus, but not to oncolysis. Further expression of the small GTPase Rac1 gene was found to be essential for both NDV replication and oncolytic activity. ${ }^{36,61}$

\section{NDV envelope proteins as key players in the oncolytic activity}

As described earlier, the $\mathrm{F}$ fusion protein is a major determinant of NDV virulence in the avian host. ${ }^{11,23,62}$ The sequence in the F0 protein associated with viral replication and pathogenicity was mapped to the cleavage site between F1 and F2 that is sensitive to cellular serine proteases. ${ }^{11}$ A main difference between the attenuated NDV-HUJ and pathogenic strains, such as MTH-68/H, lies in this sequence. The cleavage site in attenuated NDV-HUJ is amino acids 112-GRQ-GR-116 and in the pathogenic NDV-MTH-68/H strain is 112-RRQ-RR-116. ${ }^{15}$ In the fertilized chicken egg, there are several extracellular serine proteases able to cleave the $\mathrm{F} 0$ precursor protein at both the mono-basic amino acid cleavage site of NDV-HUJ and at the multi-basic amino acid site of NDV MTH-68/H. However, in mammalian tissues, due to a deficiency in some of these serine proteases, cleavage of the F0 precursor of NDV-HUJ is inefficient. Thus, excess noninfectious NDV-HUJ particles are produced and the spread of viral progeny is limited in mammalian tissues. ${ }^{15}$ Addition of exogenous trypsin to the progeny NDV-HUJ particles produced in mammalian tissues results in cleavage of F0 and consequent infectivity. ${ }^{15} \mathrm{NDV}-\mathrm{HUJ}$, albeit the mono-basic amino acid at the F0 cleavage site, exhibits oncolytic activity similar to that of the NDV-MTH-68/H strain, in a number of tumors, including melanoma, carcinoma of the lung, and colon carcinoma. . $^{1,30,34}$

It is of interest to investigate whether replacement of the F0 cleavage site in NDV-HUJ with a multi-basic amino acid sequence would further enhance the antitumor properties of this attenuated strain. Indeed, when the F0 gene of attenuated NDV (Hitchner-B1) was genetically modified to encode for a multi-basic amino acid cleavage site (rNDV/F3aa), therapeutic activity was improved when compared with that of the parent virus in immune competent tumor-bearing mice. ${ }^{39,41}$ The rNDV/F3aa mutant was effective in the treatment of highly fatal peritoneal dissemination of gastric cancer, as well as in melanoma. ${ }^{41,63}$ The mutant virus was shown to be highly fusogenic, thus causing extensive apoptosis. ${ }^{38,39,41}$ Insertion of the influenza IFN antagonist gene NS1 into mutant rNDV/F3aa further increased the oncolytic activity of the virus, as demonstrated by regression of B16 melanoma in mice and its effect on a variety of human tumor cell lines. ${ }^{41}$

$\mathrm{HN}$, the second surface glycoprotein of NDV, is a multifunctional protein responsible for the attachment of the virus to the sialic acid receptor and assists the $\mathrm{F}$ protein in cell fusion and viral entry. ${ }^{64}$ In addition, the $\mathrm{HN}$ protein induces apoptosis in chicken embryo fibroblasts and in MCF-7 human tumor cells. ${ }^{65}$ Based on this information, it was suggested that the HN protein may also play a role in the oncolytic activity of NDV. ${ }^{65}$

It may well be that cooperation of the $\mathrm{HN}$ and $\mathrm{F}$ proteins plays a role in the induction of autophagy, syncytia formation, and consequently the oncolytic activity of NDV. ${ }^{14,66}$ Cellular autophagy was observed in various tissues (heart, liver, spleen, lung, and kidney) following NDV infection in chickens. ${ }^{66}$ Autophagy, as a mechanism facilitating NDV replication, was also reported in infected glioma cells in culture. ${ }^{67}$ Moreover, pharmacological enhancement of autophagy-stimulated replication and the oncolytic activity of the NDV/FMW strain in drug-resistant lung cancer cells points to the importance of autophagy in oncolysis. ${ }^{68}$

\section{ECM molecules in solid tumor tissue restrict viral spread and oncolysis}

Effective treatment of solid tumors with oncolytic viruses requires spread of progeny virus following the initial infection. Viral spread may be restricted by a variety of mechanisms, including innate and adaptive immune responses in the tissue, and by ECM molecules that the virus has to transverse during spread. Kolodkin-Gal et al have reported that HSV1 selectively infects colon carcinoma tissues in organ culture as compared with normal tissue due to differences in the organization of the ECM barrier in normal and tumor tissues. Digestion of the ECM in normal colon tissue enabled efficient infection by HSV1, and consequently the selectivity of the virus to the cancer tissue diminished. ${ }^{44}$ Other studies have shown that insertion of genes encoding for matrix metalloproteinases (MMPs) into the genome of HSV1 and adenovirus endows the recombinant viruses with improved spread and oncolytic activity in solid tumors due to efficient degradation of extracellular protein in the tumor tissue.$^{69,70}$ Nevertheless, the clinical application of MMP-armed viruses may be challenging because these proteolytic enzymes have been associated with metastatic spread, and in fact inhibitors 
against these proteases have been developed to counteract metastatic cancer. ${ }^{71-73}$ We have studied the effect of ECM molecules on NDV infection and spread in mouse models of lung and melanoma cancers. Indeed, intratumoral injection of NDV together with the ECM degrading enzymes, collagenase and heparanase, enabled competent virus spread in the tumor, resulting in efficient oncolysis..$^{30}$ These observations should be taken into account in the development of oncolytic viruses and especially in the selection of the type of tumor to be treated.

\section{NDV and immunotherapy}

In addition to its direct cytolytic effect, the antitumor activity of NDV is associated with activation of both innate and adaptive immunity against tumor antigens in conjunction with viral antigens. ${ }^{48,74}$ Adaptive immunity, involving antibodies and cytotoxic $\mathrm{T}$ lymphocytes, is strongly stimulated following infection of the natural avian host as well as mammals. ${ }^{39,47,75}$ Since NDV selectively infects tumor cells, viral antigens are preferentially displayed on tumor cells in conjunction with tumor antigens. In addition, NDV infection results in upregulation of major histocompatibility complex class I molecules, to appropriately display the viral and tumor antigens to the immune system. ${ }^{76}$ The infected tumor cells are subsequently recognized and destroyed, mainly by natural killer cells and CD8+ cytotoxic T lymphocytes.

Two therapeutic approaches have been pursued to exploit the strong immune response against NDV-infected tumors, ie, direct intratumoral injection of the virus and infection of tumor cells ex vivo followed by injection of cell extracts or intact cells to stimulate the immune system. To explore the capacity of NDV to directly induce antitumoral immunity, we have developed a unique syngeneic mouse model of orthotropic colon carcinoma, with Balb/C mouse colon carcinoma cells (CT26) injected directly into the colon. ${ }^{42}$ The CT26 cell line was selected since it is permissive to infection by the attenuated NDV-HUJ, yet no cytopathic effect is noticed in infected cells (unpublished data). Thus, the oncolytic activity of NDV, due to the host immune responses and not because of direct cytopathic activity, could be studied. A single injection of NDV-HUJ directly into the developing tumor in the mouse resulted in major tumor regression (eight of 15 mice showed no signs of tumors 2 weeks post viral injection, Figure 6), while all the control mice injected intratumorally with phosphatebuffered saline died by day 21 . Upon rechallenge of the eight tumor-free mice with an additional injection of CT26 cells into the colon tissue, seven of the mice did

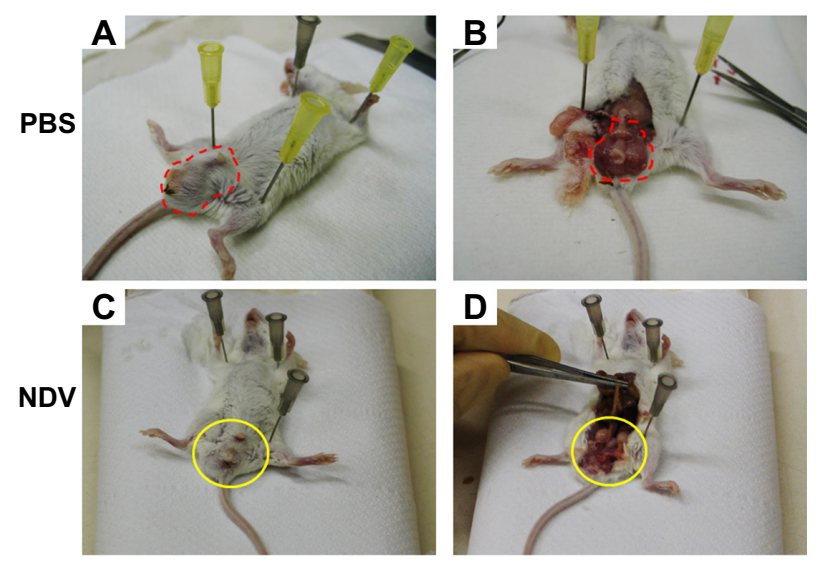

Figure 6 Intratumoral injection of NDV-HUJ results in reduced tumor mass in mice. Notes: Mouse colon tumor cells CT26-Luc were injected orthotopically into the $\mathrm{Balb} / \mathrm{C}$ mouse rectum. ${ }^{42} \mathrm{After} 5$ days, the mice were injected intratumorally with NDV$\mathrm{HUJ}\left(10^{7} \mathrm{IU}\right)$, or with PBS. Sixteen days post intratumoral injection of NDV, mice were sacrificed and observed. Observation of the tumor mass area in the mice, before and after dissection (marked with red dashed line), following treatment with phosphatebuffered saline (A and B) or with NDV-HUJ (C and D) (marked with yellow circle). Abbreviations: NDV, Newcastle disease virus; HUJ, Hebrew University Jerusalem; PBS, phosphate-buffered saline.

not show any reappearance of tumor (Figure 7). It should be noted that intact CT26 tumor cells in the control nontreated mice may have also poorly stimulated the immune system response. ${ }^{77,78}$ Nevertheless, without intratumoral virus injection, the immunogenicity of these tumor cells was not sufficient to block tumor progression. These results point to the role of NDV in stimulating an effective antitumor response, either as an adjuvant or in conjunction with tumor antigens expressed by the tumor cells.

Moreover, the survival of the re-challenged mice, shows that once immune memory against the cancer cells has been established, the animals are well protected from challenge with the same type of tumor cells. In yet another study, Yaacov et al showed that treatment of $\mathrm{C} 57 / \mathrm{BL}$ mice bearing a syngeneic tumor (Lewis lung carcinoma cells [3LL]) by intravenous or subcutaneous injection of NDV-HUJ resulted in inhibition of both primary and distant metastasis and prolonged survival time. ${ }^{15}$ The replicative NDV-MTH-68/H and the attenuated NDV-HUJ strain demonstrated a similar oncolytic effect in this mouse tumor model, again pointing to the importance of immune responses in the oncolytic activity of NDV.

In agreement, injection of NDV into mice with implanted B16 melanoma tumors was shown to induce a systemic inflammatory effect, leading to infiltration with tumor-specific CD4+ and CD8+ T-cells, and an antitumor effect in distant metastases. ${ }^{49}$ The contribution of the immune response to the oncolytic activity of NDV was further demonstrated using recombinant NDV armed with the interleukin-2 gene. Subcutaneous injection of this armed recombinant NDV into mice 

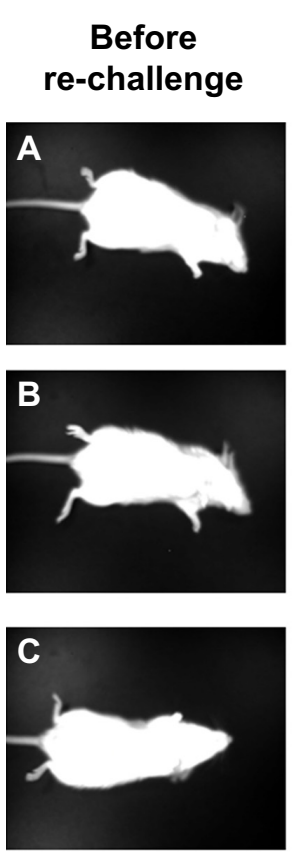

5 days post cell injection
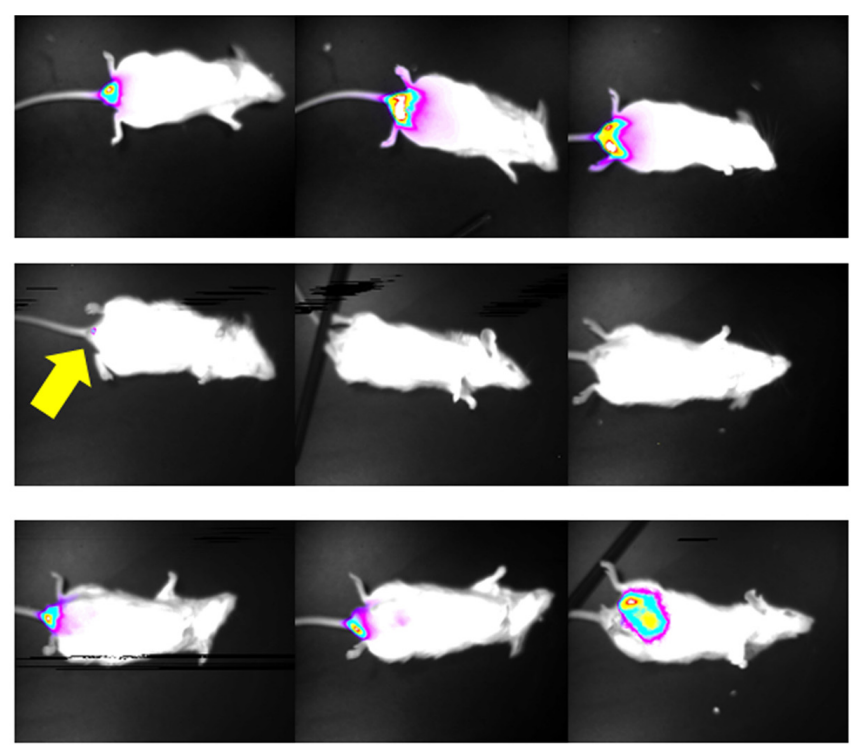

Figure $7 \mathrm{NDV}-\mathrm{HUJ}$ induces immune memory against tumor cells in mice. Three months post tumor regression of mice treated with NDV-HUJ, the eight convalescent mice were challenged again with CT26-Luc cells.

Notes: The mice were observed under a charge coupled device camera at different times post CT26-Luc cell injection. ${ }^{42}$ (A) Naïve mice injected for the first time with CT26-Luc cells, developed tumor that progressed with time. (B) Seven of eight convalescent mice (treated with NDV-HUJ) were resistant to tumor development upon challenge with CT26-Luc cells. Minor tumor appearance was evident 5 days post cell injection (indicated by yellow arrow), that disappeared by day I2. (C) One of the eight convalescent mice developed a significant tumor post CT26-Luc challenge.

Abbreviations: NDV, Newcastle disease virus; HUJ, Hebrew University Jerusalem.

implanted with CT26 colon carcinoma cells resulted in marked tumor regression. ${ }^{39}$ Overexpression of interleukin-2 following injection with this virus contributed to a T-cell dependent immune response against tumor-associated antigen, leading to more complete tumor regression and protection from a subsequent tumor challenge with the same tumor cells. ${ }^{39}$ These observations may open up a new approach for treatment with a recombinant NDV expressing a specific tumor-associated antigen for use as a therapeutic cancer vaccine. ${ }^{79}$

The relative contributions of the direct cytopathic activity of the virus and the immune responses to its antigens may vary from tumor to tumor and between the NDV strains. Taken together, these results emphasize the importance of the host innate response and immune memory in the oncolytic activity of NDV. Schirrmacher et al have pioneered yet another approach to the treatment of cancer by employing autologous tumor vaccine (ATV-NDV) through application of autologous irradiated tumor cells infected ex vivo with NDV. This treatment protocol activates both the innate and adaptive immune systems towards the cancerous tissue, resulting in effective oncolysis. ${ }^{74,80-82}$ Several clinical trials based on this approach in patients harboring melanoma and colon carcinoma metastasis showed immune memory against the tumor, tumor regression, and increased survival. ${ }^{47}$
In summary, NDV is an effective immune adjuvant, provoking both innate and adaptive immune responses for the generation of an antitumor immune response. ${ }^{76}$

\section{Clinical trials}

Clinical applications of NDV in cancer therapy have preceded all preclinical studies with the virus, and in fact were carried out prior to any safety evaluation of such treatment. Initial observations were recorded in cancer patients following vaccination or contracting a natural viral infection. ${ }^{7,8}$ The replicative NDV-MTH-68/H strain, first used in clinical trials, was introduced to patients with a variety of cancers through the intravenous route or by inhalation. Overall, positive outcomes have been reported and no serious adverse effects were noted. ${ }^{19}$ However, these early treatments were carried out in an uncontrolled fashion and it is therefore difficult to draw conclusions related to the efficacy and toxicity of NDV in cancer patients. ${ }^{19}$

Three general approaches were applied in more recent clinical studies: direct injection of free infectious virus, injection of protein lysates derived from tumor cells infected in culture by NDV, and injection of intact fixed tumor cells infected in culture by NDV (Table 1). Application of either infected whole cells or cell lysates relies only on the adjuvant 
Table I Selected clinical trials using Newcastle disease virus

\begin{tabular}{|c|c|c|c|c|}
\hline NDV strain & Tumor type & Treatment mode & Phase & Reference \\
\hline PV70I & Solid cancers & Intravenous & I & 21,55 \\
\hline NDV-HUJ & Glioblastoma & Intravenous & I-II & 25 \\
\hline NDV-MTH-68/H & Various advanced cancer & & $\begin{array}{l}\text { Uncontrolled clinical } \\
\text { experiments (II) }\end{array}$ & 19 \\
\hline Ulster & Melanoma & ATV-NDV & II/III & 86 \\
\hline \multirow[t]{4}{*}{ Ulster } & Ovarian cancer & ATV-NDV & II & 47 \\
\hline & Stomach cancer & & & \\
\hline & Pancreatic cancer & & & \\
\hline & Glioblastoma & & & \\
\hline Ulster & Colorectal cancer with metastases & ATV-NDV & III & 87 \\
\hline Ulster & Glioblastoma & ATV-NDV & II & 88 \\
\hline Ulster & Metastatic colorectal cancer & ATV-NDV & II & 89,90 \\
\hline Ulster & Ovarian & ATV-NDV & II & 91 \\
\hline Ulster & Advanced colorectal cancer & ATV-NDV & II & 92 \\
\hline Ulster & Metastatic renal cell carcinoma & ATV-NDV & II & 93 \\
\hline Ulster & Various advanced tumors & ATV-NDV & II & 94 \\
\hline LaSota & Colorectal cancer & ATV-NDV & III & 95 \\
\hline LaSota & Advanced gastrointestinal tumors & ATV-NDV & ॥ & 95 \\
\hline
\end{tabular}

Note: Table indicates the Newcastle disease virus strain, treatment modality, and clinical phase, and is summarized from the National Cancer Institute (http://www.cancer.gov). ${ }^{84}$ Abbreviation: ATV-NDV, autologous virus modified tumor vaccine using Newcastle disease virus.

activity of NDV proteins, expressed in cells to stimulate the patient immune system to respond against the tumor. Notwithstanding, the activity of the whole cell vaccine is higher than that of the oncolysate. Since the aim of these approaches has been to elicit tumor-specific natural killer cells and cytotoxic $\mathrm{CD} 8+$ cells against tumor antigens, tumors like melanoma and renal cell carcinoma, known to selectively express immunogenic proteins, were selected..$^{83}$ To further enhance the immunogenicity of the therapeutic vaccine, some of the patients were also treated with interleukin-2 or IFN- $\gamma$. The cells used in these studies were usually derived from the patient's own tumor (autologous vaccine) and in some trials from stable cell lines (allogeneic vaccine) grown in culture. The major difference between infected intact cells and lysed cell protein preparations, such as antitumor vaccine, is related to the NDV strain used for infection of the cell cultures, ie, a non-lytic-attenuated NDV strain for whole cell vaccine and a lytic virus for preparation of a cell extract. Exposure of the patient's immune system to the viral antigens in the two therapeutic vaccines is expected to differ. While for a whole cell vaccine the immune system responds mainly to the viral envelope proteins $\mathrm{F}$ and $\mathrm{HN}$, as well to processed viral peptides in the context of major histocompatibility complex I on the cell surface, in cell extract preparations all viral proteins are exposed.

The Phase I/II clinical trials carried out with the two therapeutic vaccines point to a positive antitumor effect, in particular with regard to overall disease-free survival ${ }^{76}$ It should be noted, however, that these conclusions are based on historical data from patients with the same type of tumor and not from a control group within the same trial.

\section{Antitumor activity after injection of free infectious NDV}

Preclinical animal models have clearly demonstrated an oncolytic effect of both attenuated and replicative NDV strains injected either systemically or directly into tumor tissue. ${ }^{39-41,79}$ Based on these findings, several Phase I/II clinical studies were carried out using either the replicative NDV-PV701 strain or the attenuated NDV-HUJ strain..$^{21,25,55}$ These initial studies demonstrated efficacy in some patients; but clearly the small numbers of participants in each of the studies do not allow clear conclusions. However, it should be noted that while no major side effects were noted in the study with the attenuated NDV-HUJ strain, injection of the replicative NDV-PV701 strain caused fatigue, fever, and low blood pressure in the patients. ${ }^{84}$ Results of clinical trials with several NDV strains, both replicative and attenuated, have been summarized by $\mathrm{Lam}^{76}$ (see also Table 1).

The effectiveness of viral oncolysis following repeated virus administration is expected to diminish over time due to eliciting of neutralizing antibodies. While data on this point are clearly missing, a clinical trial in 14 patients suffering from glioblastoma multiforme given repeated injections of NDV-HUJ indicated that NDV antibodies developed slowly and had either plateaued or started to decrease by week 8 of treatment. ${ }^{25}$ Further, one patient who achieved complete tumor regression developed antibodies to NDV early on and 
to the same level as other nonresponding patients. This may suggest minimal interference of NDV antibodies with the oncolytic activity. A similar observation was made by Pecora et al in a clinical study of patients harboring advanced solid cancers. $^{21}$

To overcome the potential neutralization of the virus by antibodies, it was suggested to use small DNA aptamers to block the antibodies in the circulation and thus shield the virus from neutralization. ${ }^{85}$ Other potential solutions to this obstacle are outlined by Russell et al. ${ }^{2}$

\section{Discussion}

The extensive preclinical data and limited clinical experience with oncolytic NDV clearly indicate its potential efficacy for a variety of lymphomas and solid tumors, including metastases. However, there are several open questions that need to be resolved in order to maximize the likelihood of success in large-scale clinical trials. First, there is a need for additional validated preclinical models to understand the mode of infection and spread of NDV in human cancerous tissues. The mouse model frequently used at the preclinical stage of antitumor drug development may not reflect certain major aspects of human disease or interaction with the virus. For example, NDV, originally an avian virus, could have different tissue tropism in mice and humans, and the immune responses of mice and humans to the virus are likely to differ. With this in mind, we have developed the organ culture system, with human cancerous and normal tissues from the same patient, as an ex vivo model to evaluate the tropism, spread, and mechanism of action of oncolytic NDV in the relevant human tumors. Based on results obtained in an ex vivo model, we now propose the application of our ex vivo model in clinical trials, as additional inclusion criteria, to those already in use, for improving the prospect of personalized treatment. A biopsy of tumor tissue from a patient is applied to organ culture and the oncolytic virus capacity to infect, spread, and destroy the tissue is followed by laboratory means. Results obtained in the ex vivo model would then serve to determine treatment parameters in the clinical phase. The ex vivo model system is of course relevant for clinical studies of direct oncolysis following injection of the virus.

Extensive preclinical studies have indicated two major modes of oncolysis with NDV, ie, selective infection and killing of tumor cells ${ }^{15,34,46}$ or indirectly through induction of specific host immune responses acting against the tumor tissue. ${ }^{47-49,80}$ In fact, both oncolytic pathways are induced following direct treatment with NDV. More studies are clearly needed to establish the contribution of each oncolytic pathway following introduction of NDV by different routes, ie, intravenous or intraperitoneal.

The choice of oncolytic NDV strain has to be determined through side-by-side comparison experiments. The pathogenic replicative NDV strains, such as PV701 and MTH-68/H, have the potential to efficiently spread in solid tumors to directly kill cells. However, the ECM and other barriers in the solid tumor may interfere and slow viral spread and thus lower the effective oncolytic outcome. Further, these replicative virus strains may evoke undesirable side effects in the patient and may pose safety problems to the environment and to medical personnel. The attenuated NDV strains, such as HUJ, Ulster, and Hitchner-B1, selectively infect tumor cells but have a limited spreading capacity. ${ }^{30}$ The attenuated NDV strains appear to better induce an antitumor immune response and do not cause an adverse reaction in patients. ${ }^{25}$

Overall, NDV is a rather safe virus for the treatment of humans, its RNA genome is stable, and pre-existing immunity to the virus in humans is absent. The virus infects many types of tumors since its receptor (sialic acid) is ubiquitous. Moreover, it has been demonstrated by us and others that NDV exerts efficient oncolytic activity in tumors resistant to cytotoxic drugs. ${ }^{34,67}$ Finally, engineering of the virus to better infect and spread in tumor tissue or for overexpression of immunogenic cytokines is a promising direction. More work is clearly required to select the proper genetic modifications that will provide the optimal oncolytic NDV.

\section{Acknowledgment}

Part of the work described in this article was supported by the Israel Science Foundation, The Israeli Academy of Sciences.

\section{Disclosure}

The authors report no conflicts of interest in this work.

\section{References}

1. Ottolino-Perry K, Diallo JS, Lichty BD, Bell JC, McCart JA. Intelligent design: combination therapy with oncolytic viruses. Mol Ther. 2010;18(2):251-263.

2. Russell SJ, Peng KW. Viruses as anticancer drugs. Trends Pharmacol Sci. 2007;28(7):326-333.

3. De Pace N. Sulla scomparsa di un enorme cancro vegetante del collo dell'utero senza cura chirurgica. [On the demise of the a huge vegetating cervical cancer without surgical care]. Ginecologia. 1912;9:82-89.

4. Cattaneo R, Miest T, Shashkova EV, Barry MA. Reprogrammed viruses as cancer therapeutics: targeted, armed and shielded. Nat Rev Microbiol. 2008;6(7):529-540

5. Huang PI, Chang JF, Kirn DH, Liu TC. Targeted genetic and viral therapy for advanced head and neck cancers. Drug Discov Today. 2009;14(11-12): 570-578.

6. Sheridan C. Amgen announces oncolytic virus shrinks tumors. Nat Biotechnol. 2013;31(6):471-472. 
7. Moore AE. Effects of viruses on tumors. Ann Rev Microbiol. 1954;8: 393-410.

8. Kapp JP. Microorganisms as antineoplastic agents in CNS tumors. Arch Neurol. 1983;40(10):637-642.

9. Ring CJ. Cytolytic viruses as potential anti-cancer agents. J Gen Virol. 2002;83 Pt 3:491-502.

10. Csatary LK. Viruses in the treatment of cancer. Lancet. 1971;2(7728): 825.

11. Lamb RA, Parks GD. Paramyxoviridae: their viruses and their replication. In: Fields BN, Knipe DM, Howley PM, editors. Fields Virology. 5th ed. Philadelphia, PA, USA: Wolters Kluwer and Lippincot Williams and Willkins; 2007.

12. Huang Z, Krishnamurthy S, Panda A, Samal SK. Newcastle disease virus $\mathrm{V}$ protein is associated with viral pathogenesis and functions as an alpha interferon antagonist. J Virol. 2003;77(16): 8676-8685.

13. Park MS, Garcia-Sastre A, Cros JF, Basler CF, Palese P. Newcastle disease virus $\mathrm{V}$ protein is a determinant of host range restriction. $J$ Virol. 2003;77(17):9522-9532.

14. de Leeuw OS, Koch G, Hartog L, Ravenshorst N, Peeters BP. Virulence of Newcastle disease virus is determined by the cleavage site of the fusion protein and by both the stem region and globular head of the haemagglutinin-neuraminidase protein. $J$ Gen Virol. 2005;86 Pt 6: 1759-1769.

15. Yaacov B, Eliahoo E, Lazar I, et al. Selective oncolytic effect of an attenuated Newcastle disease virus (NDV-HUJ) in lung tumors. Cancer Gene Ther. 2008;15(12):795-807.

16. Alexander DJ. Newcastle disease and other avian paramyxoviruses. Rev Sci Tech. 2000;19(2):443-462.

17. Dortmans JC, Rottier PJ, Koch G, Peeters BP. The viral replication complex is associated with the virulence of Newcastle disease virus. J Virol. 2010;84(19):10113-10120.

18. Kumar R, Tiwari AK, Chaturvedi U, et al. Velogenic Newcastle disease virus as an oncolytic virotherapeutics: in vitro characterization. Appl Biochem Biotechnol. 2012;167(7):2005-2022.

19. Csatary LK, Eckhardt S, Bukosza I, et al. Attenuated veterinary virus vaccine for the treatment of cancer. Cancer Detect Prev. 1993;17(6): 619-627.

20. Csatary LK, Moss RW, Beuth J, Torocsik B, Szeberenyi J, Bakacs T. Beneficial treatment of patients with advanced cancer using a Newcastle disease virus vaccine (MTH-68/H). Anticancer Res. 1999;19(1B): 635-638.

21. Pecora AL, Rizvi N, Cohen GI, et al. Phase I trial of intravenous administration of PV701, an oncolytic virus, in patients with advanced solid cancers. J Clin Oncol. 2002;20(9):2251-2266.

22. Spalatin J, Turner AJ, Hanson RP. Observations on the transmissibility of lentogenic strains of Newcastle disease virus: significance of variables. Avian Dis. 1976;20(2):361-368.

23. Nagai Y, Klenk HD, Rott R. Proteolytic cleavage of the viral glycoproteins and its significance for the virulence of Newcastle disease virus. Virology. 1976;72(2):494-508.

24. Toyoda T, Sakaguchi T, Imai K, et al. Structural comparison of the cleavage-activation site of the fusion glycoprotein between virulent and avirulent strains of Newcastle disease virus. Virology. 1987;158(1):242-247.

25. Freeman AI, Zakay-Rones Z, Gomori JM, et al. Phase I/II trial of intravenous NDV-HUJ oncolytic virus in recurrent glioblastoma multiforme. Mol Ther. 2006;13(1):221-228.

26. Lorence RM, Katubig BB, Reichard KW, et al. Complete regression of human fibrosarcoma xenografts after local Newcastle disease virus therapy. Cancer Res. 1994;54(23):6017-6021.

27. Schirrmacher V, Jurianz K, Roth C, Griesbach A, Bonifer R, Zawatzky R. Tumor stimulator cell modification by infection with Newcastle disease virus: analysis of effects and mechanism in MLTC-CML cultures. Int J Oncol. 1999;14(2):205-215.

28. Sinkovics JG, Horvath JC. Newcastle disease virus (NDV): brief history of its oncolytic strains. J Clin Virol. 2000;16(1):1-15.
29. Wheelock EF, Dingle JH. Observations on the repeated administration of viruses to a patient with acute leukemia. A preliminary report. $N$ Engl J Med. 1964;271:645-651.

30. Yaacov B, Lazar I, Tayeb S, et al. Extracellular matrix constituents interfere with Newcastle disease virus spread in solid tissue and diminish its potential oncolytic activity. J Gen Virol. 2012;93 Pt 8:1664-1672.

31. Zamarin D, Palese P. Oncolytic Newcastle disease virus for cancer therapy: old challenges and new directions. Fut Microbiol. 2012;7(3): 347-367.

32. Stram Y, Shchori D, Chinitch Y, David D, Molad T, Samina I. Molecular characterization of an unassigned Israeli Newcastle disease virus isolate. Avian Dis. 1998;42(4):746-751.

33. Yissum Research Development and Theravir Management. Inventors: Zakay-Rones Z, Panet A, Irving C. Compositions and methods for treatment of cancer. United States Patent US 7223389 B2. March 11, 2004.

34. Lazar I, Yaacov B, Shiloach T, et al. The oncolytic activity of Newcastle disease virus NDV-HUJ on chemoresistant primary melanoma cells is dependent on the proapoptotic activity of the inhibitor of apoptosis protein Livin. J Virol. 2010;84(1):639-646.

35. Mansour M, Palese P, Zamarin D. Oncolytic specificity of Newcastle disease virus is mediated by selectivity for apoptosis-resistant cells. J Virol. 2011;85(12):6015-6023.

36. Puhlmann J, Puehler F, Mumberg D, Boukamp P, Beier R. Rac1 is required for oncolytic NDV replication in human cancer cells and establishes a link between tumorigenesis and sensitivity to oncolytic virus. Oncogene. 2010;29(15):2205-2216.

37. Cheon DJ, Orsulic S. Mouse models of cancer. Annu Rev Pathol. 2011;6: 95-119.

38. Elankumaran S, Chavan V, Qiao D, et al. Type I interferon-sensitive recombinant newcastle disease virus for oncolytic virotherapy. JVirol. 2010;84(8):3835-3844.

39. Vigil A, Park MS, Martinez O, et al. Use of reverse genetics to enhance the oncolytic properties of Newcastle disease virus. Cancer Res. 2007;67(17):8285-8292.

40. Zamarin D, Martinez-Sobrido L, Kelly K, et al. Enhancement of oncolytic properties of recombinant newcastle disease virus through antagonism of cellular innate immune responses. Mol Ther. 2009;17(4):697-706.

41. Zamarin D, Vigil A, Kelly K, Garcia-Sastre A, Fong Y. Genetically engineered Newcastle disease virus for malignant melanoma therapy. Gene Ther. 2009;16(6):796-804.

42. Kolodkin-Gal D, Zamir G, Pikarski E, et al. A novel system to study adenovirus tropism to normal and malignant colon tissues. Virology. 2007;357(1):91-101.

43. Weisblum Y, Panet A, Zakay-Rones Z, et al. Modeling of human cytomegalovirus maternal-fetal transmission in a novel decidual organ culture. J Virol. 2011;85(24):13204-13213.

44. Kolodkin-Gal D, Zamir G, Edden Y, et al. Herpes simplex virus type 1 preferentially targets human colon carcinoma: role of extracellular matrix. J Virol. 2008;82(2):999-1010.

45. Kolodkin-Gal D, Edden Y, Hartshtark Z, et al. Herpes simplex virus delivery to orthotopic rectal carcinoma results in an efficient and selective antitumor effect. Gene Ther. 2009;16(7):905-915.

46. Bar-Eli N, Giloh H, Schlesinger M, Zakay-Rones Z. Preferential cytotoxic effect of Newcastle disease virus on lymphoma cells. J Cancer Res Clin Oncol. 1996;122(7):409-415.

47. Schirrmacher V. Clinical trials of antitumor vaccination with an autologous tumor cell vaccine modified by virus infection: improvement of patient survival based on improved antitumor immune memory. Cancer Immunol Immunother. 2005;54(6):587-598.

48. Schirrmacher V, Bai L, Umansky V, Yu L, Xing Y, Qian Z. Newcastle disease virus activates macrophages for anti-tumor activity. Int J Oncol. 2000;16(2):363-373.

49. Zamarin D, Holmgaard RB, Subudhi SK, et al. Localized oncolytic virotherapy overcomes systemic tumor resistance to immune checkpoint blockade immunotherapy. Sci Transl Med. 2014;6(226): iqwul226ra232. 
50. Krishnamurthy S, Takimoto T, Scroggs RA, Portner A. Differentially regulated interferon response determines the outcome of Newcastle disease virus infection in normal and tumor cell lines. JVirol. 2006;80(11): 5145-5155.

51. Reichard KW, Lorence RM, Cascino CJ, et al. Newcastle disease virus selectively kills human tumor cells. J Surg Res. 1992;52(5):448-453.

52. Garcia-Sastre A, Egorov A, Matassov D, et al. Influenza A virus lacking the NS1 gene replicates in interferon-deficient systems. Virology. 1998;252(2):324-330.

53. Lieu KG, Brice A, Wiltzer L, et al. The rabies virus interferon antagonist $P$ protein interacts with activated STAT3 and inhibits Gp130 receptor signaling. J Virol. 2013;87(14):8261-8265.

54. Wang X, Li M, Zheng H, et al. Influenza A virus NS1 protein prevents activation of NF-kappaB and induction of alpha/beta interferon. JVirol. 2000;74(24):11566-11573.

55. Lorence RM, Roberts MS, O’Neil JD, et al. Phase 1 clinical experience using intravenous administration of PV701, an oncolytic Newcastle disease virus. Curr Cancer Drug Targets. 2007;7(2):157-167.

56. Elankumaran S, Rockemann D, Samal SK. Newcastle disease virus exerts oncolysis by both intrinsic and extrinsic caspase-dependent pathways of cell death. J Virol. 2006;80(15):7522-7534.

57. Lazar I, Perlman R, Lotem M, Peretz T, Ben-Yehuda D, Kadouri L. The clinical effect of the inhibitor of apopotosis protein livin in melanoma. Oncology. 2012;82(4):197-204.

58. Abd-Elrahman I, Hershko K, Neuman T, Nachmias B, Perlman R, Ben-Yehuda D. The inhibitor of apoptosis protein Livin (ML-IAP) plays a dual role in tumorigenicity. Cancer Res. 2009;69(13):5475-5480.

59. Nachmias B, Ashhab Y, Bucholtz V, et al. Caspase-mediated cleavage converts Livin from an antiapoptotic to a proapoptotic factor: implications for drug-resistant melanoma. Cancer Res. 2003;63(19): 6340-6349.

60. Molouki A, Yusoff K. NDV-induced apoptosis in absence of Bax; evidence of involvement of apoptotic proteins upstream of mitochondria. Virol J. 2012;9:179.

61. Chan AY, Coniglio SJ, Chuang YY, et al. Roles of the Rac1 and Rac3 GTPases in human tumor cell invasion. Oncogene. 2005;24(53): 7821-7829.

62. Sergel-Germano T, McQuain C, Morrison T. Mutations in the fusion peptide and heptad repeat regions of the Newcastle disease virus fusion protein block fusion. J Virol. 1994;68(11):7654-7658.

63. Song KY, Wong J, Gonzalez L, Sheng G, Zamarin D, Fong Y. Antitumor efficacy of viral therapy using genetically engineered Newcastle disease virus [NDV(F3aa)-GFP] for peritoneally disseminated gastric cancer. J Mol Med. 2010;88(6):589-596.

64. Ravindra PV, Tiwari AK, Sharma B, et al. HN protein of Newcastle disease virus causes apoptosis in chicken embryo fibroblast cells. Arch Virol. 2008;153(4):749-754.

65. Ghrici M, El Zowalaty M, Omar AR, Ideris A. Induction of apoptosis in MCF-7 cells by the hemagglutinin-neuraminidase glycoprotein of Newcastle disease virus Malaysian strain AF2240. Oncol Rep. 2013;30(3) 1035-1044.

66. Sun Y, Yu S, Ding N, et al. Autophagy benefits the replication of Newcastle disease virus in chicken cells and tissues. J Virol. 2014;88(1): 525-537.

67. Meng S, Zhou Z, Chen F, et al. Newcastle disease virus induces apoptosis in cisplatin-resistant human lung adenocarcinoma A549 cells in vitro and in vivo. Cancer Lett. 2012;317(1):56-64.

68. Jiang K, Li Y, Zhu Q, et al. Pharmacological modulation of autophagy enhances Newcastle disease virus-mediated oncolysis in drug-resistant lung cancer cells. BMC Cancer. 2014;14:551.

69. Cheng J, Sauthoff H, Huang Y, et al. Human matrix metalloproteinase-8 gene delivery increases the oncolytic activity of a replicating adenovirus. Mol Ther. 2007;15(11):1982-1990.

70. Hong CS, Fellows W, Niranjan A, et al. Ectopic matrix metalloproteinase-9 expression in human brain tumor cells enhances oncolytic HSV vector infection. Gene Ther. 2010;17(10):1200-1205.

71. Deryugina EI, Quigley JP. Matrix metalloproteinases and tumor metastasis. Cancer Metastasis Rev. 2006;25(1):9-34.
72. Folgueras AR, Pendas AM, Sanchez LM, Lopez-Otin C. Matrix metalloproteinases in cancer: from new functions to improved inhibition strategies. Int J Dev Biol. 2004;48(5-6):411-424.

73. Kaimal R, Aljumaily R, Tressel SL, et al. Selective blockade of matrix metalloprotease-14 with a monoclonal antibody abrogates invasion, angiogenesis, and tumor growth in ovarian cancer. Cancer Res. 2013;73(8):2457-2467.

74. Schirrmacher V, Fournier P. Newcastle disease virus: a promising vector for viral therapy, immune therapy, and gene therapy of cancer. Methods Mol Biol. 2009;542:565-605.

75. Jarahian M, Watzl C, Fournier P, et al. Activation of natural killer cells by newcastle disease virus hemagglutinin-neuraminidase. $J$ Virol. 2009;83(16):8108-8121.

76. Lam HY, Yeap SK, Rasoli M, et al. Safety and clinical usage of newcastle disease virus in cancer therapy. J Biomed Biotechnol. 2011;2011: 718710 .

77. Wang XY, Li Y, Manjili MH, Repasky EA, Pardoll DM, Subjeck JR. Hsp110 over-expression increases the immunogenicity of the murine CT26 colon tumor. Cancer Immunol Immunother. 2002;51(6): 311-319.

78. Zhou R, Huang WJ, Ma C, et al. HOCl oxidation-modified CT26 cell vaccine inhibits colon tumor growth in a mouse model. Asian Pac Cancer Prev. 2012;13(8):4037-4043.

79. Vigil A, Martinez O, Chua MA, Garcia-Sastre A. Recombinant Newcastle disease virus as a vaccine vector for cancer therapy. Mol Ther. 2008;16(11):1883-1890.

80. Fournier P, Arnold A, Wilden H, Schirrmacher V. Newcastle disease virus induces pro-inflammatory conditions and type I interferon for counter-acting Treg activity. Int J Oncol. 2012;40(3): $840-850$.

81. Janke M, Peeters B, Zhao H, et al. Activation of human T cells by a tumor vaccine infected with recombinant Newcastle disease virus producing IL-2. Int J Oncol. 2008;33(4):823-832.

82. Schirrmacher V, Haas C, Bonifer R, Ertel C. Virus potentiation of tumor vaccine T-cell stimulatory capacity requires cell surface binding but not infection. Clin Cancer Res. 1997;3(7):1135-1148.

83. Coulie PG, Van den Eynde BJ, van der Bruggen P, Boon T. Tumour antigens recognized by $\mathrm{T}$ lymphocytes: at the core of cancer immunotherapy. Nat Rev Cancer. 2014;14(2):135-146.

84. National Cancer Institute, National Institues of Health. Available from: http://www.cancer.gov/cancertopics/pdq/cam/NDV/HealthProfessional/ page5. Accessed December 1, 2014.

85. Muharemagic D, Zamay A, Ghobadloo SM, et al. Aptamer-facilitated protection of oncolytic virus from neutralizing antibodies. Mol Ther Nucleic Acids. 2014;3:e167.

86. Voit C, Kron M, Schwurzer-Voit M, Sterry W. Intradermal injection of Newcastle disease virus-modified autologous melanoma cell lysate and interleukin-2 for adjuvant treatment of melanoma patients with resectable stage III disease. J Dtsch Dermatol Ges. 2003;1(2): 120-125.

87. Schulze T, Kemmner W, Weitz J, Wernecke KD, Schirrmacher V, Schlag PM. Efficiency of adjuvant active specific immunization with Newcastle disease virus modified tumor cells in colorectal cancer patients following resection of liver metastases: results of a prospective randomized trial. Cancer Immunol Immunother. 2009;58(1): 61-69.

88. Steiner HH, Bonsanto MM, Beckhove P, et al. Antitumor vaccination of patients with glioblastoma multiforme: a pilot study to assess feasibility, safety, and clinical benefit. J Clin Oncol. 2004;22(21):4272-4281.

89. Liebrich W, Schlag P, Manasterski M, et al. In vitro and clinical characterisation of a Newcastle disease virus-modified autologous tumour cell vaccine for treatment of colorectal cancer patients. Eur J Cancer. 1991;27(6):703-710.

90. Schlag P, Manasterski M, Gerneth T, et al. Active specific immunotherapy with Newcastle-disease-virus-modified autologous tumor cells following resection of liver metastases in colorectal cancer. First evaluation of clinical response of a phase II-trial. Cancer Immunol Immunother. 1992;35(5):325-330. 
91. Mobus V, Horn S, Stock M, Schirrmacher V. Tumor cell vaccination for gynecological tumors. Hybridoma. 1993;12(5):543-547.

92. Ockert D, Schirrmacher V, Beck N, et al. Newcastle disease virusinfected intact autologous tumor cell vaccine for adjuvant active specific immunotherapy of resected colorectal carcinoma. Clin Cancer Res. 1996;2(1):21-28.

93. Pomer S, Schirrmacher V, Thiele R, Lohrke H, Brkovic D, Staehler G. Tumor response and 4 year survival-data of patients with advanced renalcell carcinoma treated with autologous tumor vaccine and subcutaneous R-IL-2 and IFN-alpha(2b). Int J Oncol. 1995;6(5):947-954.
94. Bohle W, Schlag P, Liebrich W, et al. Postoperative active specific immunization in colorectal cancer patients with virus-modified autologous tumor-cell vaccine. First clinical results with tumor-cell vaccines modified with live but avirulent Newcastle disease virus. Cancer. 1990;66(7):1517-1523.

95. Liang W, Wang H, Sun TM, et al. Application of autologous tumor cell vaccine and NDV vaccine in treatment of tumors of digestive tract. World J Gastroenterol. 2003;9(3):495-498.

\section{Publish your work in this journal}

Oncolytic Virotherapy is an international, peer-reviewed, open access online journal publishing original research, study protocols, reviews, editorials and commentaries on all aspects of oncolytic virology, namely the application of oncolytic viruses for the treatment of cancer. Specific topics in the journal include: Rationale and theoretical aspects of oncolytic virotherapy including in vitro, in vivo and mathematical

Submit your manuscript here: http://www.dovepress.com/oncolytic-virotherapy-journal

\section{Dovepress}

modeling; and practical application and problem solving in the clinic including identification of potential responders through biomarkers and genetic profiling. The manuscript management system is completely online and includes a very quick and fair peer-review system, which is all easy to use. Visit http://www.dovepress.com/ testimonials.php to read real quotes from published authors. 